\title{
MAPEANDO O LUGAR DA MULHER DOCENTE NA UNIVERSIDADE FEDERAL DE SANTA CATARINA
}

MAPPING THE PLACE OF WOMAN PROFESSOR AT FEDERAL UNIVERSITY OF SANTA CATARINA

\section{Luana do Rocio Taborda ${ }^{1}$ e Ana Martina Baron Engerroff ${ }^{2}$}

RECEBIDO EM: 09/06/2017 | APROVADO EM: 30/07/2017

DOI: $10.5902 / 2317175827596$

\section{RESUMO}

O objetivo central deste trabalho é refletir acerca do lugar e o não-lugar da mulher docente na universidade. Inicialmente, nos debruçamos sobre estudos de novas epistemologias que agregam a discussão sobre gênero, trazendo-se a preocupação com a reprodução da "colonialidade de gênero", problematizando a concepção "normáscula" da ciência e as buscas por rupturas com a mesma. Em um segundo momento, apresentamos dados quantitativos que atestam um estado de não paridade acerca da presença docente de mulheres e homens na academia no âmbito da Universidade Federal de Santa Catarina (UFSC), discutindo os pressupostos metodológicos da pesquisa. Nossos dados corroboram uma permanência das desigualdades de gênero na universidade, em que, embora haja uma aparente igualdade nos números sobre os docentes segundo sexo, uma percepção micro, segundo áreas, departamentos e titulação, demonstra a segmentação entre áreas tipicamente determinadas masculinas e femininas, com preponderância de assentos masculinos em áreas consagradas e mais prestigiadas.

Palavras-chave: Mulher; Gênero; Docência; Universidade

\footnotetext{
${ }^{1}$ Mestranda em Sociologia Política pela Universidade Federal de Santa Catarina. Graduada e licenciada em Ciências Sociais pela mesma universidade. Bolsista CAPES. E-mail: Iuanadorocio@gmail.com.

2 Mestranda do programa de pós-graduação em Sociologia Política da Universidade Federal de Santa Catarina (UFSC), Florianópolis, Brasil. E-mail: anambaron@hotmail.com.
} 


\begin{abstract}
The main goal of this paper is to reflect about the place and the non-place of women in the academy. Initially, we analyze the studies of new epistemologies which add the discussion on gender, on the concern with the "coloniality of gender" reproduction, problematizing the "normale" conception of science and seeking for breaks with it. At second, we introduce quantitative data attesting to a state of non-parity between women and men professors at the brazilian Federal University of Santa Catarina (UFSC), discussing the methodological assumptions of the research. Our data corroborates the permanence of gender inequalities at the university, where, although an general overview makes it seem like there is an apparent equality in the numbers of teachers by gender, a more detailed view by areas, departments and tenure positions shows the segmentation between typically male and female areas, with a preponderance of men in consecrated, more prestigious areas.
\end{abstract}

Keywords: Woman; Gender; Teaching; University.

\title{
1 Introdução
}

Neste artigo propomos a discussão do lugar ocupado pelas mulheres no âmbito da ciência, mais especificamente na carreira docente universitária. Diversos estudos têm se dedicado ao tema gênero e ciência, que explicitam que essa é uma atividade historicamente reservada ao homem. ${ }^{2}$ Através da secularização e das revoluções liberais a partir dos séculos XVII e XVIII se estabelece uma separação entre o sujeito e objeto (na defesa da objetividade e neutralidade), do sagrado e do profano, do público e do privado, reforçando papéis sexuais e exclusão da mulher da esfera pública, alcançando nessa lógica o universo científico (NOVAES, 2015).

Ao pensar a mulher e a ciência, Schienbinger (2001, p. 24-26) aponta para duas vertentes iniciais: de um feminismo liberal, que suscitava a ideia de direitos iguais entre homens e mulheres, implicando na luta pela inclusão da mulher na produção do conhecimento (mas sem questionar o modelo masculino-cultural imbricado na ciência); e, a partir dos anos 80, um feminismo da diferença que, afastando um determinismo biológico da suposta incapacidade natural das muIheres, defendia diferenças de características entre homens e mulheres, donde o feminino poderia agregar em uma nova forma de fazer ciência. Embora essa última vertente conseguisse refutar a ideia de que a ciência possui um gênero neutro e que valores geralmente atribuídos às mulheres foram excluídos da ciência, não conseguia superar os estereótipos de gênero, preconizando uma ciência feita pelo "jeito" feminino. Ambas as ideias, assim, não rompem com o modelo da ciência, atribuindo somente à mulher o sucesso ou o fracasso, o que poderia levar a crer que, aumentando o número de mulheres ingressantes nas cadeiras acadêmicas, ter-se-ia uma cultura científica diferente.

$2 \quad$ Como em Leta (2003), Melo e Lastres (2004), Hayashi et al. (2007); Silva e Ribeiro (2014) e, mais sistematicamente Schiebinger (2001). 
Neste ponto, Estébanez (2003) coloca a importância de unir diversos modelos, lutando tanto pela inclusão da mulher (numericamente) na produção do conhecimento, como também produzindo novas epistemologias que possam contribuir na desnaturalização da neutralidade de gênero da ciência. No entanto, a autora também reconhece a dificuldade, em especial de países latino-americanos, de superar a brecha informativa acerca da situação da mulher na ciência, ante a escassez do desenvolvimento de estatísticas e outros meios que forneçam parâmetros atualizados e confiáveis para elaborar políticas e estudos específicos.

Frente a esse panorama, pesquisas têm percorrido a dados quantitativos, demonstrando o contínuo aumento da participação da mulher na produção do conhecimento científico, seja na observação entre países (ESTEBANEZ, 2013) ou ainda internamente (TABAK, 2002). Segundo censo de 2010 do CNPQ (2013), seguindo essa tendência, dos 128,6 mil pesquisadores cadastrados, metade são mulheres, sendo que em 1995, de cada 100 pesquisadores, apenas 39 eram do sexo feminino. Mesmo assim, o aumento percentual de mulheres na academia não necessariamente reflete mudanças de paradigmas da ciência ou relações paritárias, o que pode ser observado pelo predomínio de homens nas lideranças de pesquisa ou prestígio de carreira e nas ciências duras (CNPQ, 2013; e HAYASHI et. Al, 2007). Neste sentido, as novas epistemologias, em especial as teorias feministas aliadas aos estudos pós-coloniais (como o caso de CONNELL, 2012), fornecem importante marco para se repensar e questionar as relações de poder existentes na composição dos paradigmas científicos.

Por isso, torna-se importante a produção de dados locais que possam trazer à luz a representatividade das mulheres no âmbito profissional, e, mais especificamente, na ciência (carreira docente). $O$ objetivo central deste trabalho é, portanto, refletir acerca do lugar (e o não-lugar) da mulher docente na Universidade Federal de Santa Catarina (UFSC), a partir de pesquisa quantitativa. Nossos dados corroboram uma permanência das desigualdades de gênero no âmbito da docência, em que, embora haja uma aparente igualdade numérica segundo sexo, em uma percepção segundo Centros, Departamentos e Titulação, demonstra-se a segmentação de áreas tipicamente determinadas masculinas e femininas, com preponderância de assentos masculinos em áreas consagradas e mais prestigiadas.

O trabalho está organizado de modo a primeiro trazer à baila a discussão das novas epistemologias que vêm pensando o gênero na produção do conhecimento. Posteriormente, discute-se a metodologia utilizada para se apresentar os dados colhidos. Com isso, compreendemos ser possível realizar um deslocamento epistemológico e contribuir com o debate em torno dos papéis de gênero da produção do conhecimento científico.

\section{Ciência e gênero: novas epistemologias.}

Traçado o panorama inicial, tem-se que a ciência não é neutra. Neste sentido, as teorias pós-coloniais ou decolonial têm buscado demonstrar como 
operam a visão deturpada do "outro", na imposição de uma visão androcêntrica e do norte-global (como se verifica em Connel, 2012). Nesta esteira, conclui Spivak (2010, p. 126) que "o subalterno não pode falar", uma vez que não há 'valor' algum atribuído a ele e, especialmente, não há um 'lugar' da mulher que seja respeitoso na lista de prioridade globais.

Connell (2014, p.24) percebe que "a concepção internacional a respeito do gênero é fortemente moldada pela teoria, metodologia e agendas que vêm do Norte global. Esta é a situação comum de quase todos os campos do conhecimento organizado." Sob as perspectivas da teoria do norte, portanto, está pressuposta uma epistemologia consolidada, dentro de uma ordem de gênero, uma estrutura de classes, que não podem ser pressupostas na periferia global, já que "estruturas de gênero e de classe são criadas sob condições únicas no mundo colonial, e não simplesmente importadas ou modificadas" (CONNELL, 2012, P. 12).

Se a mulher não guarda um local de respeito como 'o outro', tampouco lhe espera posição melhor como intelectual, sendo historicamente relegada à condição secundária. Por isso, novamente Spivak (2010, p. 126) coloca como imperativo intelectual da mulher que a mesma não rejeite essa posição de poder sobre o conhecimento, na importância de tomar à frente das discussões dessas relações desiguais. O plano de fundo colocado é que "o pessoal é político", expressão discutida por Varikas (1996) e dá a dimensão do fazer intencional que se interroga sobre as relações de poder (dentre elas a dominação do sexo) e o poder político.

Diante disso, vemos no início do século XXI uma tentativa de 'revisão epistemológica' de autores clássicos nas ciências humanas, em que a questão da tratativa sobre o gênero - como o mesmo é representado ou sua sintomática ausência de consideração - coloca-se como uma das vertentes para repensar os clássicos. O lugar é de um movimento de reconhecimento de que a compreensão e explicação dos fenômenos sociais, culturais ou históricos se dão de maneira genderizada, mesmo que de forma automática e subjetiva ou ainda transversal (BANDEIRA, ALMEIDA, 2014).

Nesta perspectiva, um importante livro coloca como foco de análise central essa preocupação de genderização na ciência, e em especial das ciências humanas, é "O gênero nas Ciências Sociais: releituras críticas de Max Weber a Bruno Latour" (CHABAUD-RYCHTER, et. Al, 2014). A obra é composta por 34 artigos, todos escritos por analistas expoentes na temática e com diferentes áreas de formação e atuação. Propõe-se uma releitura dos clássicos sobre o lugar delegado ao feminino (ou da sua gritante ausência), extravasando assim a discussão sobre implicações das questões de gênero nos fenômenos a serem estudados por esses teóricos e colocando em evidência a dominação masculina e do masculino nas ciências sociais "normásculas".

Por toda a composição da obra há uma preocupação em desnudar um ethos masculinizado contido em autores em que, embora se constituam como pilares científicos, a perspectiva do masculino 'contamina' toda a suposta objetividade e neutralidade das suas teorias e métodos. Sintomático disto é que, 
sendo os autores escolhidos segundo sua maior aparição nos currículos disciplinares e influência na consolidação do conhecimento científico moderno, dos 34 artigos, apenas um seja sobre uma mulher, Hannah Arendt, cuja "presença incômoda na pilha de obras masculinas, como um grãozinho de ervilha debaixo do colchão da princesa cuja pele é muito delicada - evoca a condição de 'exceção' que ela conquistou no meio de um pensamento político dominado pelos homens (...)" (CHABAUD-RYCHTER, et al., 2014, p.06).

No entanto, outra dimensão acena-se importante na recriação do pensamento social, propondo-se não só as discussões das relações de gênero, mas também a ideia de colonialidade do saber, compondo a "colonialidade de gênero", tal como proposto pela filósofa Maria Lugones (2007 apud CONNELL, 2014). Fica em evidência a importância do lugar de fala e a herança da conquista colonial e suas enormes influências nas relações de gênero, que, tal como todos os demais aspectos culturais e sociais, sofreram um ataque que abalou ou mesmo soterrou suas anteriores formas de organização. Um exemplo de uma dimensão que no sul diferencia-se bastante do norte, e deveria ter mais importância teórica e analítica, é a questão do gênero e da terra. No Brasil, a existência de muitos movimentos de mulheres camponesas e advindas do meio rural é essencial para se entender toda a extensão da disputa pela terra, mas em um modelo normativo teórico advindo do norte, essa temática não é prioridade, o que já foi debatido por Paulilo (1987 e 2010). Assim, como no caso da relação entre o gênero e a terra, "cada vez mais reconhecemos a colonialidade do gênero e a análise de gênero que emerge de um mundo majoritariamente pós-colonial. Isto inclui diferentes abordagens para a identidade, o poder e o Estado (...)" (CONNELL, 2014, P.11).

Connell (2014) ainda defende que as questões-chave acerca do gênero do Sul global seriam de um cunho social (daí a necessidade de uma abordagem diferenciada), já que no norte as mesmas questões giram em torno de identidade e métodos desconstrucionistas. Assim sendo, as questões que nos são principais seriam: como pensar teoricamente a partir de outra perspectiva (paradigmática) e colocando a mulher e as estruturas normásculas em evidência? Em se considerando que o lugar importa (geopolítica do conhecimento), qual o lugar da mulher que produz e transmite conhecimento, ou seja, a docente de ensino superior?

Como colocado por Schienbinger (2001, p. 37), é justamente por ser a ciência moderna um produto de centenas de anos de exclusão das mulheres, que o processo de trazer as mulheres para a ciência exige "profundas mudanças estruturais na cultura, métodos e conteúdo da ciência." $E$, continuando, não se pode esperar que "alegremente" as mulheres tenham êxito em um empreendimento que, em sua origem, foi estruturado para excluí-las.

Sendo assim, especialmente tomando essas divisões sexuais do trabalho e da necessidade de produzir dados locais, podemos aproximar da realidade brasileira, para percebermos os avanços (ou não) da posição da mulher como docente e pertencente ao meio acadêmico. Dentro do contexto universitá- 
rio, embora haja o discurso por não discriminação e busca da inclusão e da paridade nas diferentes áreas, estudos empíricos demonstram lugares ainda bastante demarcados, como na concentração das docentes em áreas como saúde e educação, e sua quase exclusão nas ciências ditas exatas e tecnológicas (HAYASHI, 2007), tornando-se importante reconhecer esse contexto de gênero e ciência em nossa universidade.

\section{A metodologia da pesquisa.}

Com a realização desta pesquisa, visamos não só verificar a quantidade de homens e mulheres docentes, mas também tornar visível os locais em que as mulheres estão presentes ou ausentes, numericamente, na carreira acadêmica na Universidade Federal de Santa Catarina. A UFSC foi fundada no ano de 1960, incorporando faculdades já existentes no estado de Santa Catarina, contando atualmente com 11 Centros de ensino ${ }^{3}$ no campus David Ferreira de Lima, no bairro Trindade em Florianópolis (além dos demais 04 campi existentes).

Ainda que se trate de uma análise preliminar, a sua importância se dá tanto para fomentar a produção científica na temática, permitindo o aprofundamento da discussão de gênero e ciência, mas também pela possibilidade de se realizar estudos comparativos e replicáveis, ante a ausência de dados a respeito de gênero e docência, tanto por parte das pesquisas acadêmicas locais, quanto por parte da própria universidade.

Sem olvidar das várias possibilidades de abordagem, focamos na pesquisa quantitativa, colhendo dados obtidos através do Departamento de Administração de Pessoal (DAP) da UFSC, com listagem contendo nome de professores ativos por centro e campi, data de admissão, jornada e titulação de progressão de carreira, além da listagem de professores titulares fornecidas pelas secretarias dos centros CFH e CTC, que utilizamos para confirmação dos dados. Desse levantamento, realizamos recortes (campi Florianópolis e docentes efetivos do nível superior) e estabelecemos as categorias "homem" e "mulher" por meio de pressuposição segundo o nome e da autodenominação contida a plataforma Lattes, que compuseram assim os dados analisados.

Em nosso levantamento, segundo a pergunta inicial "qual a quantidade de homens e mulheres docentes da UFSC segundo sexo?", nos vimos frente à necessidade de organização, via software SPSS Statistics, ferramenta tecnológica para auxiliar na análise estatística e sistematização dos dados. Do mesmo passo, foi realizada seleção frente a população total de docentes da UFSC (2.421), excluindo campus de outras cidade e docentes do ensino básico, com amostra final totalizando 2.157 docentes. O recorte temporal, por sua vez, refere-se aos docentes da UFSC ativos em Junho/2016. ${ }^{4}$

\footnotetext{
3 São estes: Centro de Filosofia e Ciências Humanas (CFH), Centro Tecnológico (CTC); Centro de Ciências Agrárias (CCA), Centro de Ciências Biológicas (CCB), Centro de Comunicação e Expressão (CCE), Centro de Ciências da Saúde (CCS), Centro de Ciências Jurídicas (CCJ), Centro de Desportos (CDS), Centro de Ciências da Educação (CED), Centro de Ciências Físicas e Matemáticas (CFM), Centro Socioeconômico (CSE). 4 Explicamos nossas escolhas metodológicas: primeiro, deixar os outros campus de fora da análise
} 
Deste modo, se a nossa pergunta principal é direcionada ao quantitativo de docentes segundo sexo na UFSC, com efeito, nossa problemática está centrada em entender relações e desigualdades de gênero no contexto universitário, guiadas por outras pesquisas que denunciam disparidade e hierarquias sexistas, e por epistemologias que se centram na dimensão do gênero, demarcando o caráter central dessa dimensão nas relações sociais.

É lugar comum ouvirmos, quanto às pesquisas e seus métodos, que os dados não falam por si mesmos. Essa afirmação compreende uma crítica, considerando que os dados necessitam ser interpretados, mesmo em se tratando de dados "processados cuidadosamente, com modelos estatísticos sofisticados" (BAUER; GASKELL; 2008, p.24). Assim, esta discussão envolve a necessidade de assumir o viés interpretativo presente, não apenas nas pesquisas ditas qualitativas, mas também nas consideradas quantitativas.

A discussão que faz a ligação entre a escolha metodológica e os paradigmas epistemológicos dimensionados é central neste trabalho. Primeiramente porque está relacionada à própria pergunta de pesquisa, que é um primeiro recorte, por ser fruto de um incômodo teórico: a não paridade entre gêneros feminino e masculino em diferentes profissões e divisão sexual do trabalho. Assim, as demais escolhas metodológicas também se constituem como recortes de pesquisa, na busca pela resposta à pergunta inicial, que circuncidam os dados e a análise, delimitando também as respostas encontradas.

\section{0 lugar da mulher docente na Universidade Federal de Santa Catarina}

Pensando a produção científica local, levantamos elementos que fornecem estimativas da proporção de mulheres e homens docentes atuantes no contexto da Universidade Federal de Santa Catarina (UFSC).

Pondera-se que os dados do último censo institucional realizado e disponibilizado pela própria UFSC em seu portal ${ }^{5}$ não integram gênero. Tal omissão corrobora em certa medida com a invisibilidade do discurso de preconceito de gênero dentro da academia observado por Silva e Ribeiro (2014, p. 454-456). Para as autoras, utilizando-se do estudo de Löwy, considerando que a ciência é um produto cultural, social e histórico representante do masculino branco, ocidental, elitista e colonial, não se pode ignorar que a ciência considerada legítima (neutra, objetiva, racional e universal), incorpora a visão de mundo das pessoas que criam essa ciência. Assim, torna-se fundamental discutir se e

\footnotetext{
justifica-se por uma particularidade destes campus em relação ao pessoal docente. A data de admissão dos docentes nos demais campus (fora de Florianópolis) é recente e, portanto, não é representativa de para os dados de professores de carreira (embora possam ser demonstrativos se, em concursos recentes, há mais mulheres contratadas. No entanto, dados dos professores substitutos excluídos da pesquisa-base já indicavam que isto não se confirma). Em segundo lugar, os professores de ensino básico (infantil, fundamental e médio) não foram computados, uma vez que o foco teórico se dá na produção científica de nível superior. Por fim, desconsideramos dados acerca dos professores substitutos, pela relatividade temporal (contratados em caráter temporário) e não causalidade aparente (em uma análise preliminar) entre contratação mais atual e aumento de número de mulheres docentes.

5 Censo disponível em: http://dpgi.seplan.ufsc.br/ufsc-em-numeros/
} 
como a produção da ciência legítima se dá a partir dos valores associados ao masculino, dos quais as mulheres são consideradas desprovidas.

Inicialmente, obteve-se a frequência de docentes homens e mulheres na UFSC, representada na Tabela 1. Embora haja um aparente equilíbrio (aproximadamente $42 \%$ de mulheres e $58 \%$ homens), isto representa que, grosso modo, a cada duas mulheres há três homens:

Tabela 1 - Docentes na UFSC segundo sexo

\begin{tabular}{ccc}
\hline & Frequência & Percentual \% \\
\hline HOMEM & 1253 & $\mathbf{5 8 , \mathbf { 1 }}$ \\
MULHER & 904 & $\mathbf{4 1 , 9}$ \\
Total & 2157 & $\mathbf{1 0 0 , 0}$ \\
\hline
\end{tabular}

Na Figura 1 há a representação do número de homens e mulheres por seu Centro. Assim, há apenas três Centros, CCS (239 mulheres e 149 homens), CCE (136 mulheres e 110 homens) e CED (109 mulheres e 50 homens), com o número de mulheres superior ao de homens. Em se tratando de Centros com maioria de homens em relação às mulheres, o CTC (318 homens e 80 mulheres), CFM (159 homens e 36 mulheres), e o CFH (123 homens e 86 mulheres), são os três Centros com maior número de homens.

Figura 1 - Docentes por Centro de Ensino

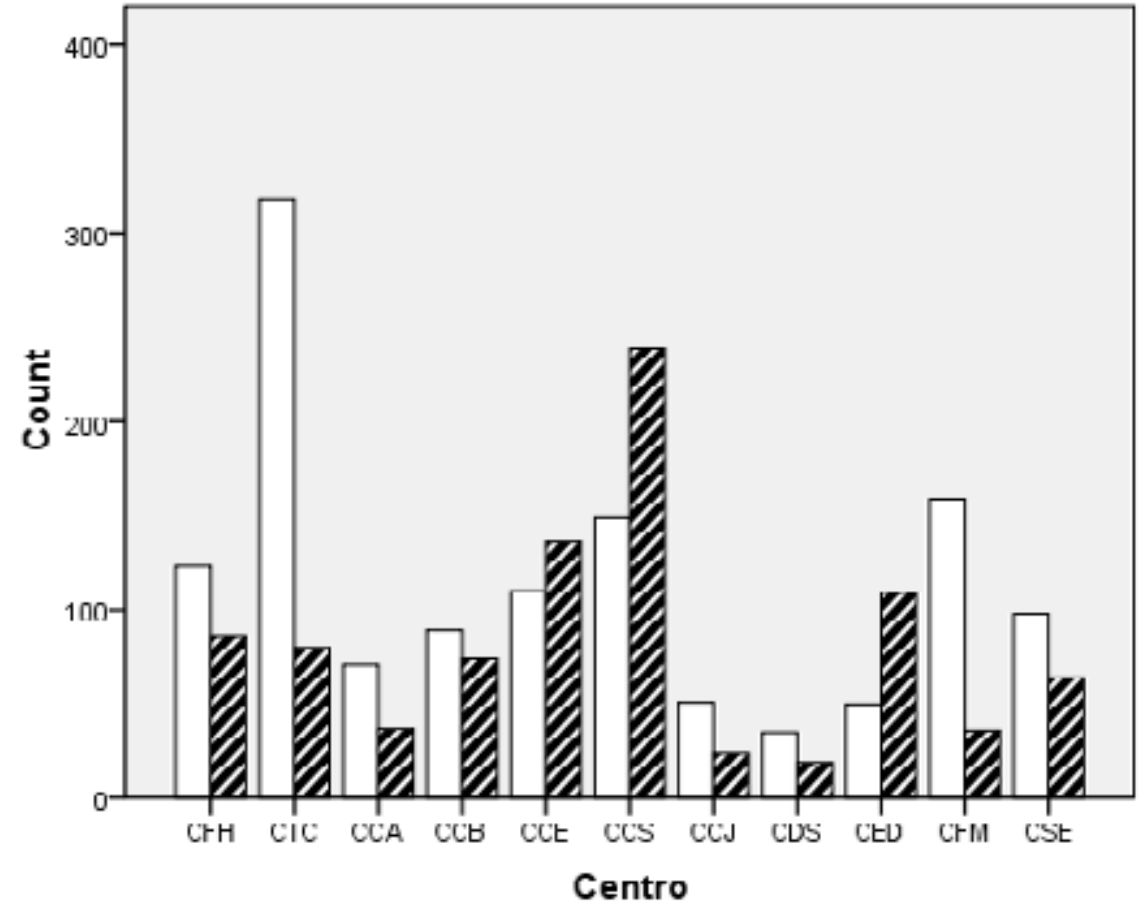


Importante destacar os Centros com maior discrepância numérica entre homens e mulheres, sendo eles: CFM $(81,5 \%$ de homens para $18,5 \%$ de mulheres), CTC (79,9\% de homens para $20,1 \%$ de mulheres) e o CCJ ( $68 \%$ de homens para 32\% de mulheres). Se os dados das ciências duras não causam surpresa, o CCJ, por sua vez, é inesperado, porquanto as ciências jurídicas geralmente passam ao largo das inferências no debate de desigualdade de gênero. ${ }^{6}$

Evidencia-se que há Centros que comportando espaços muito discrepantes que poderiam enviesar os dados, como o caso do CTC, o maior do campus, contando com 398 docentes e o CCS, com 388 professores (o CCE, terceiro maior, conta com uma diferença grande para com este, com 246 professores). No entanto, é justamente através desses dois Centros (tecnológico e saúde) que temos um importante comparativo: no primeiro, há flagrante dominância masculina ( $79,9 \%$ homens e $20,1 \%$ mulheres), enquanto que no segundo as professoras são predominantes (61,6\% mulheres e $38,4 \%$ homens). A aparente 'compensação', que poderia levar ao entendimento de equilíbrio entre gênero na universidade, não se confirma, na medida em que, considerando apenas esses dois Centros, numericamente os homens ainda são superiores $(59,4 \%$ de homens e $40,6 \%$ de mulheres, ou seja, para cada 03 homens, temos 02 mulheres), refletindo o percentual de homens e mulheres na UFSC.

Relevante destacar que, apesar de não existir qualquer Departamento na UFSC sem homens, o inverso não ocorre: em dois Departamentos, DAS - Departamento de Automação e Sistemas (do CTC) e ENR - Engenharia Rural (do CCA), não há mulher para contar história. A demarcação de gênero masculino nas áreas (departamentos) ligadas à engenharia corrobora com a premissa histórica de um lugar reservado ao masculino. Em se pensando na técnica e nas ciências ditas duras, matemáticas, físicas e químicas, também seguem o mesmo viés de dominação masculina (cerca de $80 \%$ são ocupadas por homens).

Por outro lado, nas áreas com uma predominância feminina (que ao contrário das masculinas, não possui caráter tão dominante), vemos áreas de atuação classicamente tidas como do universo da mulher: na educação $(68,5 \%$ de docentes mulheres), e, como já colocado, na saúde (quase $62 \%$ composto de mulheres). Interessante notar que nos Departamentos do Centro de Ciências da Saúde (CCS) há a predominância feminina em áreas que exigem maior contato com o paciente (enfermagem NFR 95\%, nutrição NTR 91\%, análises clínicas ACL $66 \%$ ) enquanto áreas com centralidade da técnica, como na Cirurgia (CLC), 93\% dos docentes são homens. Em uma clara diferenciação entre as áreas de ocupação, a UFSC ainda guarda um contexto de lugares demarcados, com preponderância de assentos masculinos em áreas consagradas e mais prestigiadas.

Esses dados corroboram com as explicações acerca da contínua (embora com exceções) exclusão da mulher das áreas ligadas às exatas e da 'pura

$6 \quad$ Foram localizados artigos envolvendo gênero no discurso jurídico (como em Alves, Melo, 2001) e sobre a profissão jurídica (como em SCIAMMARELLA, FRAGALE FILHO, 2015), mas não discutindo a academia, que poderia ser um elemento formador importante para a continuidade do discurso misógino dentro do universo do Direito apontado nos dois estudos. 
técnica'; e da "afeição" do feminino à educação e enfermagem trazidas por Bitencourt (2006), baseando-se na ideia de socialização do masculino e feminino. A educação destinaria às meninas valores considerados simbolicamente ao feminino e o inverso, ao masculino, constituindo papéis sociais que orientam papéis de gênero para homens e mulheres. As meninas não são estimuladas a estudar matemática, incorporando o discurso de que essa ciência ou os seus desdobramentos, como as engenharias, não são do seu mundo, afastando-as dessas áreas e aproximando-as daquelas em que as características ditas do feminino, como a sensibilidade, são valorizadas, como a educação e enfermagem. Além disso, pode-se aproveitar a ideia de segregação no âmbito científico em Bagdassarian (in Hayashi et al, 2007, p. 180), tanto no sentido horizontal quanto vertical. A segregação horizontal diz respeito às disciplinas, com as mulheres mais concentradas em ciências biológicas e médicas, e com baixa representação nas disciplinas "duras", como a física e engenharia. A segregação vertical, por sua vez, diz respeito ao avanço na carreira acadêmica, em que as mulheres cientistas se caracterizam por ocupar postos não permanentes, tenho maior taxa de abandono ou de não continuidade de carreira, o que é percebido quando se analisa a carreira de titular na UFSC.

Projetando os dados para a carreira docente, verifica-se que na UFSC há 272 Titulares docentes ativos (12,6\% do total). A carreira de titular é um marco importante não só para ganhos salariais, mas também representa o ápice da progressão de um docente de órgão federal e que está ligada à herança eurocêntrica (cátedras). Ao tomar esses dados, deve-se ter em vista que por mais de década não houve progressão para Titular ou concurso próprio, passando com as recentes normativas à progressão com defesa de memorial e/ou nova tese. ${ }^{7}$ As regras para a progressão comportam uma série de provas de produção acadêmica e longa dedicação à pesquisa, ensino e extensão, além da aprovação do candidato a titular frente aos seus pares. Isto implica dizer que, para ser titular, não basta o tempo na universidade, mas sim uma trajetória de pesquisador robusta, especialmente como liderança de pesquisas e núcleos, cargos de chefia, dentre outros.

Assim, considerando docentes Titulares na UFSC, tem-se $75,7 \%$ de docentes homens, para $24,3 \%$ de docentes mulheres Titulares.

\begin{tabular}{c|c|c|c|c}
\multicolumn{6}{l}{ Tabela 2 - Titular por sexo na UFSC } \\
\hline TITULARES & SIM & $\%$ & NÃO & TOTAL \\
\hline HOMENS & 206 & $75,7 \%$ & 1047 & 1253 \\
MULHERES & 66 & $24,3 \%$ & 838 & 904 \\
TOTAL & 272 & $100 \%$ & 1885 & 2157 \\
\hline
\end{tabular}

$\frac{\overline{\text { Fonte: autoria própria. }}}{7 \quad \text { Há diversos fatores que interferiram no vácuo temporal de progressão funcional para titular que }}$ merecem maior investigação, dentre eles a instabilidade do regime previdenciário aplicado até então para a progressão. Há também docentes concursados diretamente para a cadeira de "professor titular". A progressão obedece às resoluções do conselho universitário (atualmente 018/Cun/2006) e, possibilitando de fato as novas defesas memorais a partir de 2013, com a lei sobre o plano de carreira docente 12.772/2012 e Portaria 982/2013 do MEC. 
Novamente, vale ressaltar o enviesamento de dados pelo Centro Tecnológico, que reserva $43 \%$ do total de Titulares (117 Titulares, ou seja, 30\% do seu centro são professores Titulares). O CTC também é o Centro que, só considerando as mulheres, promove o segundo maior ingresso percentual das docentes Titulares (o CCA é o primeiro). Demonstra-se pelos dados que o CTC guarda uma intensa preocupação com a carreira que não se verifica nos outros Centros, o que pode ser justificado, por hipótese, pelo angariamento desse Centro de financiamento privados e públicos volumosos e o prestígio econômico e social da área (além de outros fatores). ${ }^{8}$ Mesmo assim, vale notar a discrepância permanente entre homens e mulheres nesse local, uma vez que, embora na totalidade dos docentes no CTC seja de $80 \%-20 \%$ (homens/muIheres), quando se trata de Titulares o percentual afunila ainda mais para as mulheres: 90\%-10\% (homens/mulheres).

Em resumo, portanto, quando se trata de Titulares, de cada 04 pessoas, 03 são homens e 01 é mulher. Algumas hipóteses podem ser levantadas na tentativa de explicar essa desigualdade observada. Tal diferença pode ser demonstrativa de uma cultura que, mesmo com discurso de não prerrogativa, ainda privilegia o masculino nos processos de defesa de banca, uma vez que as características desejáveis da ciência e de seus pares são àquelas cultivadas ao homem. Outra hipótese relaciona-se a uma maior dificuldade ainda encontrada pelas mulheres docentes em relação ao acúmulo de jornadas (duplas e triplas) entre a academia e uma divisão desigual de tarefas no contexto mais privado de suas existências, o que pode impactar diretamente na progressão de carreira. ${ }^{9} \mathrm{~A}$ desigual distribuição de bolsas de pesquisa e lideranças entre homens e mulheres (como aponta o estudo de Melo; Lastres, 2004) também pode ser fator influente para possibilitar à mulher alçar a condição de docente titular.

Em se tratando de dados sobre pesquisadores no Brasil, segundo o CNPQ (2013), como já colocado, o número de mulheres cientistas já se iguala ao de homens, embora o mesmo não possa ser dito quando tratamos de cargos de liderança, como na coordenação de Centros, Departamentos e cursos, aliada a liderança de pesquisas dentro de núcleos e laboratórios, em que a liderança feminina ainda é relativamente menor. Os dados do CNPQ corroboram a divisão demarcada por sexo segundo áreas clássicas do masculino e feminino. Embora uma já igualdade numérica de pesquisadores segundo sexo, os dados sobre as bolsas produtividade do CNPQ também demonstram disparidade segundo o sexo dos pesquisadores. Em 2012 (CNPQ, 2014), apenas 35,6\% do número de bolsistas eram de mulheres, o que corrobora a tese de que a presença de mu-

$8 \quad$ O critério de antiguidade docente na instituição não nos parece ser tão relevante para a carreira de titular, uma vez que pudemos observar, grosso modo, que há diversos docentes com muito tempo de casa mas sem progredir na carreira, necessitando assim de uma melhor aprofundamento da questão. O mesmo vale para o período de fundação dos Centros, não havendo aparente relação para que uns tenham mais Titulares que outros, tão antigos quanto.

$9 \quad$ Em pesquisa recente divulgada e realizada por órgãos ligados ao comércio (TREVISAN, 2016) destacou-se que "36\% das mulheres dizem dividir com marido as tarefas de casa igualmente", mas, ao mesmo tempo, $75,8 \%$ das mulheres dizem que são as principais responsáveis pela limpeza na casa onde moram, contra apenas $8,9 \%$ que dizem que a tarefa não tem responsável fixo, demonstrando o caráter "acessório" da divisão de tarefas. 
Iheres decresce conforme aumenta a hierarquia acadêmica, já que os critérios a bolsa produtividade incluem titulação, produção e participação acadêmica.

De outro norte (ou do outro lado do rio, como se diz na UFSC, vide BITECOURT, 2006), observa-se que o $\mathrm{CFH}$, Centro destinado à Filosofia e Humanidades, detém em seu corpo docente a maioria de homens (58,9\%), cuja proporção em Titulares se conserva (09 homens e 07 mulheres). A distribuição de Titulares por Departamentos, no entanto, tende a ser discrepante uma vez que, conforme Tabela 3, verifica-se que há Departamentos em que não há qualquer titular e outros (caso da Filosofia), que detém 06 Titulares, todos homens.

Tabela 3 Docentes por titular e por sexo no $\mathrm{CFH}$

\begin{tabular}{|c|c|c|c|c|c|c|c|c|c|c|}
\hline \multirow[b]{2}{*}{ Centro/Dptos } & \multicolumn{4}{|c|}{ HOMEM } & \multicolumn{4}{|c|}{ MULHER } & \multirow[b]{2}{*}{$\begin{array}{l}\text { TOTAL } \\
\text { GERAL }\end{array}$} & \multirow{2}{*}{$\begin{array}{c}\text { TOTAL } \\
\text { TITULAR }\end{array}$} \\
\hline & GERAL & $\%$ & TIITULAR & $\%$ & GERAL & $\%$ & TIITULAR & $\%$ & & \\
\hline CFH & 123 & 58,9 & 09 & 56,3 & 86 & 41,1 & 07 & 43,8 & 209 & 16 \\
\hline ANT - ANTROPOLOGIA & 10 & 41,7 & 01 & 33,3 & 14 & 58,3 & 03 & 66,7 & 24 & 04 \\
\hline $\begin{array}{l}\text { CSO-SOCIOLOGIA E } \\
\text { CIÊNCIA POLIITICA }\end{array}$ & 19 & 73,1 & 0 & 0 & 07 & 26,9 & 01 & 100 & 26 & 01 \\
\hline CEM - MUSEOLOGIA & 02 & 50 & 0 & 0 & 02 & 50 & 0 & 0 & 04 & 0 \\
\hline FIL - FILOSOFIA & 22 & 73,3 & 06 & 100 & 08 & 26,7 & 0 & 0 & 30 & 06 \\
\hline GCN - GEOCIÊNCIAS & 36 & 73,5 & 0 & 0 & 13 & 26,5 & 0 & 0 & 49 & 0 \\
\hline HST - HISTÓRIA & 17 & 54,8 & 01 & 50 & 14 & 45,2 & 01 & 50 & 31 & 02 \\
\hline PSI - PSICOLOGIA & 17 & 37,8 & 01 & 25 & 28 & 62,2 & 03 & 75 & 45 & 04 \\
\hline
\end{tabular}

Por fim, destaque ao Departamento de Antropologia, com núcleo de pesquisa dedicado às questões de gênero e referência na instituição, que detém o corpo docente de maioria mulher, assim como no cargo de Titular, guardando aparente equilíbrio entre gêneros. O Departamento de Sociologia e Ciência Política (CSO), por sua vez até junho de 2016, denota uma predominância masculina ( $73,1 \%$ dos docentes, para $26,9 \%$ de mulheres), mas possui em seus quadros uma mulher Titular e nenhum homem. Oposto a uma tendência imaginada de que esses números tenderão a se equilibrar, há nas Ciências Sociais um aparente processo de masculinização do seu corpo docente, haja vista que nos concursos dos últimos 05 anos (2011-2016), das 06 cadeiras ocupadas (dentre as quais oriundas de vagas de docentes mulheres), 05 foram ocupadas por homens.

\section{Conclusões}

Este estudo empírico teve como foco manter a proximidade com o referencial teórico apresentado e das mudanças de paradigmas já apontados. Ao nos debruçarmos sobre o estudo dos teóricos considerados clássicos das ciências sociais (ou da sociologia), torna-se latente o questionamento de gênero, em especial pela não representatividade (o não lugar da mulher no rol dos 
clássicos). Como a obra de CHABAUD-RYCHTER (Et al, 2014) nos proporciona entender, é preciso problematizar a objetividade desses teóricos, e nos atentarmos às influências misóginas e de uma amarga cegueira e influência que as relações de gênero das respectivas atmosferas de relações sociais temporais tiveram nas suas teorias. Em outras palavras, discutir a influência que as muIheres dos grandes homens e os debates sobre as questões de gênero da época obtiveram sob suas obras, e em consequência, na forma como as ciências sociais vem se constituindo, sob os pilares fundacionais desses teóricos clássicos.

Preocupações com a bagagem estritamente construída sob o olhar masculino da ciência são essenciais para um movimento de rupturas e busca por novas epistemologias científicas. Isso, aliado a uma atenção e precaução para com a reprodução de uma colonialidade de gênero, assim como o processo de colonialidade do saber, são as pré-disposições para esta ruptura para com uma "normáscula" científica.

Assim, nossos dados iniciais demonstram como a UFSC, embora a um olhar mais macro, pareça possuir uma aparente igualdade nos números sobre os docentes segundo sexo, a análise a um nível mais micro, segundo áreas e departamentos, ainda demonstra um ethos segmentado e dividido entre áreas determinantes masculinas e femininas. No caso dos cargos de professores Titulares, a predominância masculina é marcante, causando inquietações e proposições de hipóteses para este fenômeno. Nesta discussão, esbarramos em questões de hierarquias acadêmicas e de prestígio segundo áreas de conhecimento, onde a escala de prestígio é diretamente proporcional a uma maior ocupação masculina. Nossos dados corroboram o apontado em outros trabalhos, como o colocado por Silva e Ribeiro (2014, p.450):

Como parte do fenômeno denominado de "teto de vidro", a existência de barreiras ao acesso a níveis de maior hierarquia e prestígio compromete, geralmente, as mulheres na construção da sua carreira na ciência. Portanto, mesmo que atualmente a participação das mulheres na ciência seja equitativa do ponto de vista numérico, a hierarquia acadêmica vai estar ocupada, sobretudo, por homens, independentemente da área do conhecimento.

A partir do dados adquiridos por meio da pesquisa quantitativa realizada com base em dados obtidos através do Departamento de Administração de Pessoal (DAP) da UFSC, as principais conclusões do estudo indicam que: I) os homens são maioria entre os docentes na UFSC $(58,1 \%-41,9 \%)$; II) os docentes homens estão localizados com grande vantagem numérica em relação às mulheres nos centros ligados às ciências duras (como tecnológico e matemática), enquanto as docentes estão mais localizadas nos centros biológico e da educação; III) os estereótipos de gênero por afinidade da área de atuação são confirmados tanto por Centros, como por Departamentos; IV) a carreira de Titular docente está mais localizada com os docentes homens $(75,7 \%$ da 
população, enquanto as mulheres são $24,3 \%$ ), confirmando a desigualdade de gênero na carreira docente.

Além disso, o estudo possibilitou apreensão da realidade local (da UFSC), para percebermos que, ainda que haja uma maior abertura para a discussão da participação da mulher na ciência e a ampliação do acesso, corrobora-se que estamos muito longe de alcançar a paridade entre homens e mulheres. Tanto em termos de Centros quanto por Departamentos, demonstrou-se que as áreas do conhecimento estão segmentadas por gênero, e ainda destinando a carreira docente em sua maior hierarquia e prestígio aos homens. Assim, por meio desta análise, procurou-se colaborar com estudos a fim de se repensar e questionar as relações de poder existentes no meio acadêmico, entendendo que evidenciar o lugar (ou não-lugar) que ocupam as mulheres na docência universitária importa.

Embaladas por um sentimento de que muito ainda falta, almejamos um caminhar para a construção do conhecimento representativo paritariamente e que admita suas limitações, cegueiras e preconceitos de gênero, presentes desde suas raízes teóricas, mas reconhecendo e valorizando o privilégio de entender essa dimensão, como um primeiro e mais importante passo para uma ruptura. Por isso, dá-se a devida importância a estudos que forneçam um panorama da real situação vivenciada nas universidades e na construção de novos paradigmas científicos epistemológicos e seu espaço dentro dos currículos acadêmicos.

\section{Referências}

ALVES, A. A. C. F. ; MELO, A. M. V. Relações de Gênero e Cultura no Discurso Jurídico. In: 10 Encontro da REDOR - Rede Feminista Norte Nordeste de Estudos e Pesquisas sobre a Mulher e Relações de Gênero, 2001, Salvador. Feminismo, Ciência e Tecnologia. Salvador: UFBA, 2001. v. 10. p. 41-41.

BANDEIRA, L. M; ALMEIDA, T. M. C. de. "Prefácio à Edição Brasileira." In: Chabaud-rychter, Danielle, Descourtures, Virginie, Devreux, Anne-Marie e Varikas, Eleni (orgs.) O gênero nas ciências sociais. Releituras críticas de Marx Weber a Bruno Latour. Braslia e São Paulo: Edunb/unesp, 2014.

BAUER, M. W.; GASKELL, G. Pesquisa qualitativa com texto, imagem e som. Um manual prático. Tradução Pedrinho A. Guareschi. 7. ed. Petropólis-RJ: Vozes, 2008.

BITENCOURT, S. M. (2006). Existe um outro lado do rio? Um diálogo com a cultura da engenharia e relação de gênero no Centro Tecnológico da UFSC. (Dissertação de Mestrado), UFSC: PPG em Sociologia Política: Florianópolis/SC.

CHABAUD-RYCHTER, D, Descourtures, Virginie, Devreux, Anne-Marie e Varikas, Eleni (orgs.) O gênero nas ciências sociais. Releituras críticas de Marx Weber a Bruno Latour. Brasília e São Paulo: Edunb/Unesp, 2014.

CONNELL, R. A iminente revolução na teoria social. Rev. bras. Ci. Soc., São Paulo, v. 27, n. 80, p. 09-20, Oct. 2012

Questões de Gênero e Justiça Social. Século XXI, Revista de Ciências Sociais, v.4, no 2, p.11-48, jan./ jun. 2014.

CNPQ. Número de mulheres cientistas já iguala o de homens. Notícia. 06 de março de 2013. Disponível em: <http://cnpq.br/noticiasviews/-/journal_content/56_INSTANCE_a6MO/10157/905361>. Acesso em jun/2016.

CNPQ. Séries históricas até 2014: quantitativos de bolsas por sexo. Disponível em: http://www.cnpq.br/serieshistoricas. Acesso em jun/2016. 
ESTEBANEZ, M. E. As mulheres na ciência regional: diagnóstico e estratégias para a igualdade. Trad. De Sabine Righett. Reportagem. Mulheres na Ciência, ComCiência, 2013. Disponível em: http://www. comciencia.br/reportagens/mulheres/10.shtml. Acesso em jun/2016.

HAYASHI, M. C. P. I. et al . Indicadores da participação feminina em Ciência e Tecnologia. Transinformação, Campinas, v. 19, n. 2, p. 169-187, Ago/2007. Disponível em: http://www.scielo.br/scielo.php?script=sci_ arttext\&pid=S010337862007000200007\&Ing=en\&nrm=iso . acesso em junho de 2016.

LETA, J. As mulheres na ciência brasileira: crescimento, contrastes e um perfil de sucesso. Estudos. av., São Paulo, v.17, n.49, p. 271-284, Dez.2003. Disponível em: <http://www.scielo.br/scielo.php?script=sci_ arttext\&pid=S0103-40142003000300016\&Ing=en\&nrm=iso>. Acesso em jun/2016.

MELO, H. P. de; LASTRES, Helena M.M.; MARQUES, Teresa C. de N. Gênero no sistema de ciência, tecnologia e inovação no Brasil. Revista Gênero, NUTEG/UFF, vol. 4, n² 2, $1^{\circ}$ semestre de 2004.

NOVAES, E. D. Entre o público e o privado: o papel da mulher nos movimentos sociais e a conquista de direitos no decorrer da história. Revista História e Cultura, v. 4, p. 50-66, 2015.

PAULILO, M. I. S. Intelectuais \& militantes e as possibilidades de diálogo. Revista Estudos Feministas (UFSC. Impresso), v. 18, p. 927-940, 2010.

PAULILO, M. I. S. O peso do trabalho leve. Ciência Hoje, Rio de Janeiro - RJ, v. 5, n.28, p. 64-70, 1987.

SCIAMMARELLA, A. P. O.; FRAGALE FILHO, Roberto. (Des)constituindo gênero no poder judiciário. Ex Aequo (Oeiras) , v. 31, p. 45-60, 2015

SCHIENBINGER, L. O feminismo mudou a ciência? São Paulo: EDUSC, 2001.

SILVA, F. F. da; RIBEIRO, Paula Regina Costa. Trajetórias de mulheres na ciência: "ser cientista" e "ser mulher". Ciência. educ. (Bauru), Bauru, v. 20, n. 2, p. 449-466, 2014. Disponível em: <http://www.scielo.br/scielo. php?script=sci_arttext\&pid=S1516-73132014000200449\&lng=en\&nrm=iso>. Acesso em junho/2016.

SPIVAK, G. C. Pode o Subalterno Falar? Belo Horizonte: Editora UFMG, 2010.

TABAK, Fanny. O laboratório de Pandora: estudos sobre ciência no feminino. Rio de Janeiro: Garamond, 2002.

VARIKAS, E. O pessoal é político: desventuras de uma promessa subversiva. Tempo. vol. 2, n. 3. Rio de Janeiro, p. 59-80, 1996. Disponível em: http://www.historia.uff.br/tempo/artigos_dossie/artg3-3.pdf Último acesso em 17 de junho de 2016. 